\title{
Brief Symptom Inventory 18
}

National Cancer Institute

\section{Source}

National Cancer Institute. Brief Symptom Inventory 18. NCI Thesaurus. Code C43524.

The Brief Symptom Inventory 18 (BSI 18) assessment gathers patient-reported data to help measure psychological distress and psychiatric disorders in medical and community populations. 